\title{
Broken Expectations in the Digital Home
}

Sara Bly

Sara Bly Consulting

24511 NW Moreland Road

North Plains, OR 97133 USA

sara@sarably.com

Bill Schilit

Intel Research

2200 Mission College Blvd

Santa Clara, CA 95052 USA

bill.schilit@intel.com

\section{David W. McDonald}

The Information School

University of Washington

Suite 370, Mary Gates Hall

Campus Box 352840

Seattle, WA 98195 USA

dwmc@u.washington.edu

\author{
Barbara Rosario \\ Intel Research \\ 2200 Mission College Blvd \\ Santa Clara, CA 95052 USA \\ barbara.rosario@intel.com \\ Ylian Saint-Hilaire \\ Intel Corporation \\ 2111 NE $25^{\text {th }}$ Avenue \\ Hillsboro, OR 97124 USA \\ ylian.saint-hilaire@intel.com
}

Copyright is held by the author/owner(s).

CHI 2006, April 22-27, 2006, Montreal, Quebec Canada.

ACM 1-59593-298-4/06/0004.

\begin{abstract}
As part of an ongoing effort to understand ease of use of digital home technologies, we undertook an exploratory study of people who use their home networks for more than just broadband Internet access. In particular, we wanted to understand the overhead, or problem-time, people spent with their home network devices. As expected, we saw issues of broken hardware and broken software. We also found that problems are often caused by broken expectations, a mismatch between what a person expects to be able to do and specific device capabilities. In this paper we explore broken expectations in the digital home with examples from our study. These observations suggest further research into the ways user expectations and activities shape the digital home experience.
\end{abstract}

\section{Keywords}

Digital home; digital living; wireless networks; ease of use; home IT; digital media; field study.

\section{ACM Classification Keywords}

H5.2 User-centered design

\section{Introduction}

The increasing sophistication and complexity of networked digital devices means people spend more time figuring out what devices to buy, how to set them up, and how to keep them working and tuned [2]. In 
describing the digital home vision at the January 2006 Consumer Electronics Show, Andreas Kluth said"1, "The only problem is that it will never happen the way the industry imagines it. For one thing the digital home is fiendishly complex. The teenager in the family would have to become full-time unpaid tech support..."

We call this overhead of making digital devices support a person's desired activities problem-time. Designers and manufacturers have worked to lessen problem-time in various ways since the inception of human-computer interaction. "Usability", "ease of use", "out-of-box (OOB) experience", and "seamless interoperability" are all terms that describe design goals to decrease the problem-time a user experiences (e.g. $[4,5,7]$ ).

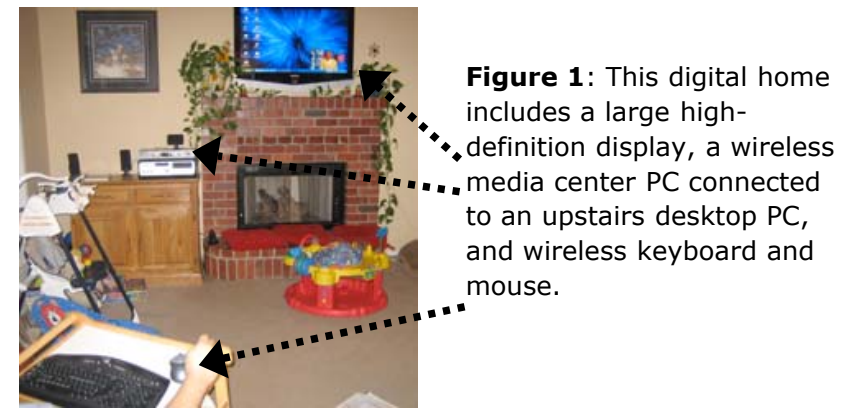

In the work described in this paper we seek to broaden our understanding of the difficulty users have with their technology as home networks grow in complexity.

Figure 1 shows a relatively straightforward example of an existing digital home. Our research question asks: what are the characteristics of problem-time in the

\footnotetext{
${ }^{1}$ NPR Marketplace Money on January 5, 2006 with Andreas Kluth
} who covers technology for the "Economist". digital home? Based on our early results we claim that complex multi-device configurations (i.e. device ensembles [6]) are not broken simply by defects in implementation or manufacture.

We find that a significant portion of problem-time is not because anything is broken - except the users' expectations of what should be working. Broken expectations occur when a person's needs and the capabilities provided in the products do not match. In general, problems arising from broken expectations are not anticipated, either by the consumer or by the manufacturer. This notion of broken expectations comes from our exploration of home technical leads, their systems and devices, and their activities and problems.

Though still in the early stages, our contribution aims to be threefold. First we raise the discussion of digital living ease-of-use and seamless interoperability to the level of everyday human activities with complex technology configurations. Second, based on our fieldwork we provide a set of illustrative examples of broken expectations. Finally, we present implications for further research in user expectations for the digital home.

\section{Exploration}

Following the tradition of user-centered design and fieldwork studies [e.g. 1,8], we began the project with three approaches to gathering user data: team member diary studies, ethnographic-style home interviews, and an online survey. These various methods allow us to triangulate our findings across different communities and different situations. 
The data and analysis reported here come from our first look at the nine in-depth home interviews. All nine participants have home networks that not only provide high-speed Internet access but also include significant media storage with wireless access. All interviewees had primary responsibility for managing their home networks. In addition to verbal questions, the interview protocol asked participants to draw their home network and, with participant permission, included a walkaround to see, photograph, and discuss the various network components and connections. All of the interviews were recorded and transcribed.

\begin{tabular}{l|l|l}
\multicolumn{2}{l}{ Participant Overview } \\
ID & Network Uses & Background \\
\hline P1 & $\begin{array}{l}\text { Wireless } \\
\text { networking; home } \\
\text { automation; digital } \\
\text { music; video } \\
\text { streaming }\end{array}$ & $\begin{array}{l}\text { An engineer in Seattle, WA; } \\
\text { extremely technically savvy } \\
\text { and a "do-it-yourself" hobbyist. } \\
\text { Works at a small company } \\
\text { building airplane parts. }\end{array}$ \\
\hline P2 & $\begin{array}{l}\text { Wireless } \\
\text { networking; home } \\
\text { automation; digital } \\
\text { music }\end{array}$ & $\begin{array}{l}\text { An engineer in Seattle, WA } \\
\text { working with P1. Very } \\
\text { knowledgeable, he still } \\
\text { describes himself as usually on } \\
\text { the "receiving end" with P1 and } \\
\text { another network savvy friend. }\end{array}$ \\
\hline P3 & $\begin{array}{l}\text { Wireless } \\
\text { networking; music } \\
\text { streaming; video } \\
\text { streaming; }\end{array}$ & $\begin{array}{l}\text { A forensic software specialist } \\
\text { and software developer in } \\
\text { Portland, OR. Participated in a } \\
\text { second interview, a "device } \\
\text { intervention" in which we } \\
\text { observed him in a talk-aloud } \\
\text { protocol as he installed a } \\
\text { wireless music system. }\end{array}$ \\
\hline P4 & $\begin{array}{l}\text { Internet access / } \\
\text { sharing; digital } \\
\text { music; computer } \\
\text { repair }\end{array}$ & $\begin{array}{l}\text { A "bored housewife" in } \\
\text { Portland, OR who builds her } \\
\text { own computers. Learned all } \\
\text { she knows online. }\end{array}$ \\
\end{tabular}

\begin{tabular}{l|l|l} 
P5 & $\begin{array}{l}\text { Wireless } \\
\text { networking; digital } \\
\text { media (music, } \\
\text { photos, video) } \\
\text { access }\end{array}$ & $\begin{array}{l}\text { A value-added reseller in } \\
\text { Portland, OR. Does rugged } \\
\text { field testing of 802.11 } \\
\text { connections to wireless } \\
\text { routers. }\end{array}$ \\
\hline P6 & $\begin{array}{l}\text { Wireless } \\
\text { networking for } \\
\text { household }\end{array}$ & $\begin{array}{l}\text { An independent software } \\
\text { engineer in San Francisco, CA } \\
\text { with two in-home renters }\end{array}$ \\
\hline P7 & $\begin{array}{l}\text { Wireless } \\
\text { networking; digital } \\
\text { music; music } \\
\text { production }\end{array}$ & $\begin{array}{l}\text { A financial analyst and } \\
\text { musician in the East Bay of the } \\
\text { San Francisco, CA metropolitan } \\
\text { area. }\end{array}$ \\
\hline P8 & $\begin{array}{l}\text { Wireless } \\
\text { networking; digital } \\
\text { music; mobile DJ } \\
\text { support }\end{array}$ & $\begin{array}{l}\text { A security guard at a local } \\
\text { meat packing plant in small- } \\
\text { town KS; DJs every other } \\
\text { weekend }\end{array}$ \\
\hline P9 & $\begin{array}{l}\text { Wireless; music } \\
\text { sharing. }\end{array}$ & $\begin{array}{l}\text { A high school senior in Wichita, } \\
\text { KS. Lives with his family and } \\
\text { works in a technology } \\
\text { department part-time. }\end{array}$ \\
& &
\end{tabular}

\section{Data}

As part of the analysis and discussion of our field data, we examined the descriptions of problems that our participants discussed. Here we offer examples from a surprising number of problems mentioned that did not involve defective or broken hardware or software.

\section{P1 Creates Work-Arounds}

$\mathrm{P} 1$ has a voice-over-IP device to add to his network. However, when he installs it as described by the manufacturer, it works but he is unable to selectively forward ports from the router built into the VoIP device to another machine that runs services he wants to access from the outside world.

P1: ...initial stuff was a little painful just because...what [VoIP manufacturer] and this voice adaptor is primarily designed 
to do is to be in between your cable modem, I mean your router. So, this would be upstream from your router and downstream from your cable modem and they wanted that but I found this to be a lot more

restrictive on opening ports...because I have a lot of server apps on here, VNC, the Media Center, some of the other things, I need the outside world to have access to the desktop, through selected ports. This guy made it really hard to do that. To, you know forward ports from the route and then forward the ports and the voice adapter through the cable modem so I wanted to put this downstream from the router and so I did do it [see Figure 2], that was kind of a pain and I did do a lot of Google searching to figure out what other people had done.

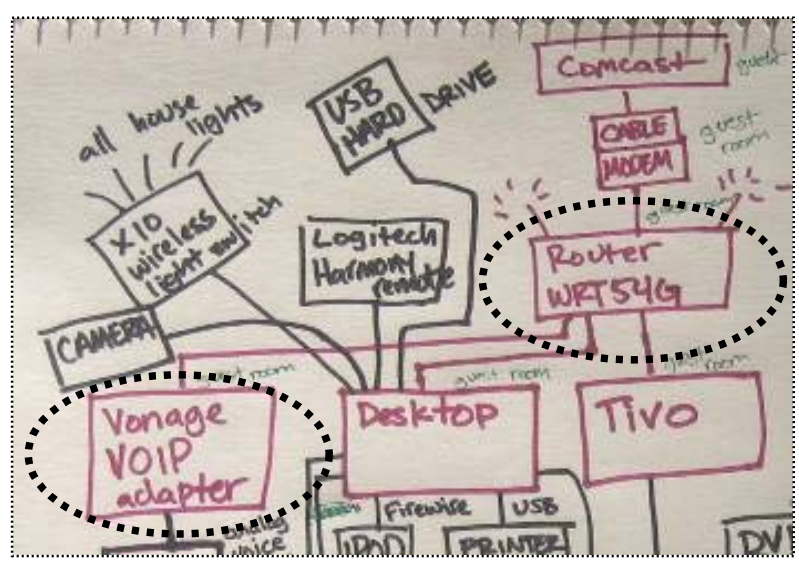

Figure 2. $\mathrm{P} 1$ 's network drawing shows the VoIP downstream.

P9 Has to Upgrade His OS

P9 got a new laptop a year ago and convinced his family to let him install a wireless network in the house. He carefully researched Linksys, D-link and Belkin on the Internet before making a purchase. Although he thought he had made all the right decision, he discovered that he couldn't install the wireless access point because he needed a more recent operating system.
P9: ... getting it to work with the computer was the most difficult part, because the computer downstairs is operating on 98 [the Windows 98 operating system]. So I had to tweak that a little bit to get it to work with the router.

Because out of all the research I did, I neglected to look at that little necessary piece of information that it has to have XP.

SB: ... how'd you make it work?

P9: Oh, I got a XP upgrade for the desktop downstairs...

P4 Gives Up on Combining Wi-Fi and a Video Card P4 recently built an entirely new computer (shown in Figure 3). The wireless card and video would not both work at the same time although each worked alone in the system. She gave up and now has a wire running across her bedroom floor to the router.

P4: ... After every reboot session the computer didn't seem to be recognizing the AGP video card and would default to VGA mode...To this day I have not been able to figure out just what the problem was between the two...after searching for patches and contacting Manufacturer Support for both the wireless card and the AGP card only to completely stump even their senior technicians, the only conclusion I could come to was "they just didn't play well together"...

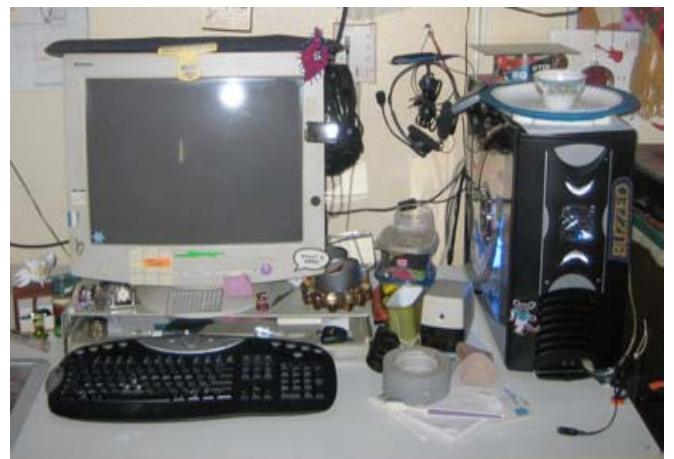

Figure 3. P4 builds her own computers. 
P3 Doesn't Get to Use A New Wireless Music Adapter P3 was excited to have a new wireless music system to install. He'd been using an old laptop as a media adapter with his stereo system. He didn't think the 802.11 b would be a problem in his $802.11 \mathrm{~g}$ network but he was mistaken.

$\mathrm{P}_{3}$ : Ah! They just have WEP! Well, that's gonna create some interesting problems; there's two forms of wireless security, there's WPA and WEP. Now, of the two, WEP is the older one, and they don't appear to handle WPA And my current wireless...is doing WPA...that says that over the short term, I'd have to reconfigure my house wireless network, and that's something I'm not willing to do at this point.”

He quickly suggests that it might be his fault,

P3: it's possible that the WEP was the only option available for $802.11 \mathrm{~b}$. I'm not really a security person. I kind of do it 'seat of the pants', so I don't really know what I'm doing. But it's conceivable that those two are linked together, and I probably should have known that.

P6 Wants to Share Video by Streaming

P6 bought a digital video recorder (DVR) and expected to be able to stream video without having to store large files.

P6: There's a [DVR] that I just recently got and I've been playing around with networking, and it hasn't been that great...like it stores the programming as just regular files, right. If you wanna access it, you have to basically download the whole thing to your computer, your local station, so the average half-hour program ends up being about 320 megabytes and change, which is a real pain when it could just be streamed. There's software out there that some third-party guy...wrote, but I don't wanna mess around with that...So I was probably just gonna build a media server and then we can all have access to it on the network... I have to basically modify the system files in [DVR] and it's not real specific as to how I would do that, and if you do it wrong the whole thing could break and you'd have to reformat the system. That would take hours.

\section{Implications for Further Investigation}

Although we had a large list of problem situations from our study participants, we found that many did not fall into categories of broken software or broken hardware. An out-of-box or usability test would have been unlikely to uncover the problems that arose. As the stories above illustrate, many problems were not anticipated, either by the consumer or by the manufacturer.

While it could be said that P9 was careless in not realizing that he needed the Windows XP operating system or that P3 should have known that an 802.11b WEP device would not be compatible with his WPA security in $802.11 \mathrm{~g}$, in practice these "oversights" cause significant problem-time and frustration for home consumers. We suggest these problems arise from broken expectations.

The broken expectations concept has implications for the adoption of more sophisticated digital home use cases as well as implications for the design of home network devices, product web sites, and a range of support tools and services. Further work in understanding broken expectations includes exploring how expectations are formed and how multiple interconnected activities cause broken expectations.

\section{The Formation of Expectations}

We have seen where expectations are broken, but we haven't yet looked at when, where and how these 
expectations arise. When do broken expectations occur as a result of lack of knowledge of the consumer, lack of clarity about the product, or similar reasons? Are misconceptions formed when consumers read product literature?

Furthermore, should broken expectations be expected? The digital home requires an ensemble of devices working together across multiple system layers. The choices of digital devices, the many ways they can be networked, the range of features, and the selection of software and settings result in a huge number of possible configurations; some of which function properly but many that do not.

Studying questions of expectations could give rise to new ways of thinking about the design of products, and more importantly device ensembles, in the context of user experience. Research and development are essential to understand how to support home technical leads even when we can't expect the technology to always get it right.

Overlapping Use Cases and Broken Expectations Use cases provide scenarios that convey how a system should interact with the end user [3]. Traditionally each use case has focused on a single system feature or a single user activity. Yet, in our interviews we saw people trying to enable overlapping use cases. In fact, these overlapping use cases often conflicted, causing broken expectations. For example, when P3 wanted to both enable streaming audio (using WEP) and maintain his secure wireless network (using WPA).

The growing complexity of the digital home may often yield conflicting use cases and requirements for technology. Use cases must become more sophisticated to reflect the multiple interconnected activities in the digital home of tomorrow.

\section{Acknowledgements}

We thank all our participants who were willing to have us in their homes and to tell us their stories. Thanks to Susan Palmiter and Chris Culy for reading and commenting on our paper.

\section{References}

[1] Beyer, H. and Holtzblatt, K. Contextual Design: Defining Customer-Centered Systems, Morgan Kauffman, San Francisco, CA, 1998

[2] Grinter, R.E., Edwards, W.K. Newman, M.W., and Ducheneaut, N. The Work to Make a Home Network Work, In Proceedings of the Ninth European Conference on Computer-Supported Cooperative Work (2005).

[3] Jacobson, I., Christerson, M., Jonsson, P. and Overgaard, G. Object-Oriented Software Engineering A Use Case Driven Approach, Addison-Wesley, Harlow, UK, 1992.

[4] Nielsen, J. Usability Engineering, Morgan

Kauffmann, San Francisco, CA, USA, 1994.

[5] Preece, J., Rogers, Y., and Sharp, H. Interaction Design, Wiley, place, USA, 2002.

[6] Schilit, B.N. and Sengupta, U. Device Ensembles, In Computer 37, 12 (2004), 56-64.

[7] Shneiderman, B. and Plaisant, C. Designing the User Interface: Strategies for Effective HumanComputer Interaction, Addison-Wesley, Reading, MA, USA, 2004.

[8] Wixon, D. and Ramey, J. (eds) Field Methods Casebook for Software Design, John Wiley \& Sons, Inc., New York, NY, USA, 1996. 